\title{
ESCOLAS REUNIDAS: UM MODELO ENTRE AS ESCOLAS ISOLADAS E OS GRUPOS ESCOLARES EM MATO GROSSO
}

\author{
Elton Castro Rodrigues dos Santos ${ }^{1}$
}

\section{RESUMO}

Objetiva-se com esse estudo investigar a criação e funcionamento das Escolas Reunidas em Mato Grosso a partir da sanção do Regulamento da Instrução Pública Primária em 1927 que modificou o cenário educacional do Estado com a implantação de novos modelos de escolas primárias no citado período. Utilizou-se como fontes principais para subsidiar as reflexões sobre as modalidades escolares que fizeram parte do cenário educacional do estado, Relatórios e Mensagens de governantes estaduais, inspetores de ensino e diretores da Instrução Pública, Legislações educacionais, disponíveis nos principais acervos e arquivos mato-grossenses. As Escolas Reunidas, por serem similares aos grupos escolares, foram uma das responsáveis pela expansão da escola graduada e pelo acesso à educação primária em Mato Grosso.

Palavras - chave: História da Educação; Escola Reunida; Mato Grosso.

\section{SCHOOLS GATHERED: A MODEL BETWEEN ISOLATED SCHOOLS AND PRIMARY SCHOOL IN MATO GROSSO}

\begin{abstract}
Objective with this study to investigate the establishment and operation of schools gathered in Mato Grosso from the sanction of the Regulation of Primary Public Instruction in 1927. Used as main sources to subsidize the reflections on the modalities schools that were part of the educational landscape of the state between the 1930s e1945, Reports and Messages state governors, teaching inspectors and directors of Public Instruction, Educational Legislation, available in major collections and archives, Mato Grosso. Schools gathered, being similar to school groups, were responsible for the expansion of the Graduate School and access to primary education in Mato Grosso.
\end{abstract}

Keywords: History of Education; School Reunited;. Mato Grosso.

\section{Introdução}

O modelo de escola graduada desponta no cenário brasileiro, nas primeiras décadas republicanas, como uma instituição educacional almejada pelos governantes brasileiros. Em seu estudo sobre a implantação da escola graduada em São Paulo, nos primórdios republicanos, Souza (1998, p. 31-32), esclarece os motivos para tal crença, as conjunturas políticas e educacionais que culminaram no processo de criação dos grupos ressaltando que esse modelo foi fruto de transformações na escola primária que passou "“[...] de uma escola de ler escrever- contar para uma escola de educação integral com um programa enriquecido e enciclopédico; de uma escola de acesso restrito para uma de acesso obrigatório, generalizado e universalizado" considerado de qualidade e que iria alavancar o desenvolvimento do país.

Outra mudança foi a adoção do método simultâneo que veio substituir o ensino individual, no qual o "professor chama sucessivamente para perto de si cada aluno e lhe dá atenção por alguns minutos"; já no método simultâneo, "o ensino não se dirige mais a um único aluno, como no modo individual, mas pode atender a cinquenta ou sessenta alunos ao mesmo tempo." (LESAGE, 1999, p. 6). 
Sobre o assunto Schueler e Magaldi, (2009, p. 37) esclarecem que o novo método consiste que "[...] um único professor trabalha simultaneamente com todos os alunos da classe, com base em atividades a serem desempenhadas por todos ao mesmo tempo". Por isso, requeria uma homogeneidade nas turmas, alcançado com a efetivação da seriação.

Os grupos escolares foram instituições propulsoras e difusoras da escola graduada no Brasil, integrando a realidade urbana e "fundaram uma representação de ensino que não apenas regulou o comportamento, reencenando cotidianamente, de professores e alunos no interior das instituições escolares, como disseminou valores e normas sociais (e educacionais)." (VIDAL, 2006, p. 9).

Para constituição dos grupos escolares eram necessário o fechamento e agrupamento de no mínimo três escolas isoladas. Estas instituições educacionais foram criadas pois se tinha, por parte dos governantes, a intenção de substituir as escolas isoladas, consideradas de baixa qualidade educacional.

De acordo com Isobe em Minas Gerais (2005, p. 2) o grupo escolar “"[...] viabilizaria práticas educativas até então inéditas e possibilitaria a organização e a realização da graduação do ensino em séries, a renovação dos métodos e processos de ensino e a introdução de novos saberes escolares nas escolas primárias mineiras". Tal fato se assemelha as prerrogativas destinadas à escola primária em Mato Grosso. As Escolas Reunidas nasce como modelo mais simplificado do que o Grupo Escolar, sem ostentar grandes prédios e nem com um número elevado de professores. As escolas Reunidas se constituíam como um modelo intermediário entre as escolas isoladas e os grupos escolares.

Com a pretensão de contribuir para os estudos sobre modelos escolares em Mato Grosso, este artigo busca investigar a criação e funcionamento das Escolas Reunidas em Mato Grosso a partir da sanção do Regulamento da Instrução Pública Primária em 1927 que modificou o cenário educacional do Estado com a implantação de novos modelos de escolas primárias no citado período. Percebe-se que a implantação das Escolas Reunidas foi um marco na educação primária de Mato Grosso.

\section{Implantação dos grupos escolares em Mato Grosso}

O cenário educacional de Mato Grosso, em 1909, era composto por 85 escolas, entretanto, "apenas funccionaram 70, conservando-se as outras fechadas por falta de professores ou de frequência escolar. Adicionando-se a este número as recentemente creadas, eleva-se o total a 104, das quaes algumas dependem ainda de instalação." (MENSAGEM, 1910, p. 8). De acordo com Sá (2007, p. 78), faltava também às escolas de Mato Grosso uma efetivação maior de inspeção escolar, não havia prédios adequados para os fins educativos, faltando também mobiliário e materiais pedagógicos. Visando mudar o quadro da educação em Mato Grosso, o Cel. Pedro Celestino Corrêa da Costa, em 1910, para que o estado se posicionasse dentro do cenário de mudanças propostas pela República, investiu na reformulação da instrução pública primária e implementou o Regulamento de 1910, instituindo assim, os grupos escolares no cenário educacional do estado (SÁ; SÁ, 2011, p.30).

O Cel. Pedro Celestino também "[...] contratou dois normalistas paulistas, Leowigildo Martins de Mello e Gustavo Kuhlmann, ambos recém-formados pela Escola Normal Caetano de Campos, com o objetivo de implementar a reorganização do ensino mato-grossense." Mello (RELATÓRIO, 1910, p. 1) explica como ocorreu o contato dos normalistas paulistas com o governo de Mato Grosso e os trâmites contratuais:

Em junho do anno de 1910, o antecessor do actual Governo, Exmo. Sr. Coronel Pedro Celestino Corrêa da Costa, dirigiu-se ao estado de S. 
Paulo, afim de obter dous normalistas para o serviço da reorganização do ensino neste Estado, patriotico emprehendimento que tão salutamente tem sido secundado pelo Governo do Exmo. Sr. Dr. Joaquim Augusto da Costa Marques. O Estado de S. Paulo, accedendo gostosamento á distinção com que o honrava o Estado irmão, designou-me e ao meu collega, professor Gustavo Kulhman, para servirmos ás ordens do Governo de Matto Grosso, a cuja disposição fomoso postos em 1 de Junho de 1910, data em que nos apresentámos no Rio de Janeiro ao Exmo. Sr. Dr. Annibal de Toledo, então delegado de Matto Grosso para os fins do contrato.

Os normalistas paulistas chegaram a Cuiabá em $1^{\circ}$ de agosto de 1910 e foram apresentados ao presidente do estado Pedro Celestino Corrêa da Costa para os trâmites contratuais. Gustavo Kuhlmann e Leowigildo de Mello orientaram a elaboração do Regulamento da Instrução Pública Primária de Mato Grosso, sancionado por meio do Decreto $\mathrm{n} \square 258$, de 20 de agosto de 1910. Tal normativa trouxe, entre outras inovações, a criação de uma escola normal e de grupos escolares no Estado. Pedro Celestino acreditava que a Reforma teria eficácia se houvesse professores habilitados para regência nas escolas mato-grossense, fato que justificava, segundo o mesmo, a criação de uma Escola Normal:

Convencido da necessidade urgente de cuidarmos do futuro da instrucção popular, base fundamental de todo o verdadeiro progresso social, que é tanto mais solido quanto mais diffundida ella se acha; e convencido tambem que o primeiro passo a dar para esse fim é a formação de bons professores, mandei contractar dois normalistas em S. Paulo, com o fim de crear aqui um Escola Normal, de que havemos mistér para a realisação desse importante objectivo [...]. (RELATÓRIO, 1910, p. 1).

Os grupos escolares, por essa nova organização educacional, deveriam ser implantados "nas sedes de distritos em que houver pelo menos seis escolas primárias, no perímetro fixado para obrigatoriedade de ensino, o Governo poderá, reunindo-as, fazê-las funcionar em um só prédio." (REGULAMENTO, 1910, p. 124).

Em Mato Grosso, o Palácio da Instrução, construído na Capital para abrigar a Escola Normal, o Liceu Cuiabano e a Escola Modelo ( $1^{\circ}$ Grupo Escolar de Mato Grosso), foi a mais imponente instituição educacional construída no estado nas primeiras décadas de 1900 e constitui, contemporaneamente, um patrimônio arquitetônico de grande relevância para a história educacional e cultural de Mato Grosso. Sobre o assunto, Cunha (2009, p. 59) esclarece:

O projeto do "Palácio da Instrução", em Cuiabá, atendeu rigorosamente no aspecto social, à organização capitalista de escola, já que a questão republicana prioritária não era prover de ensino um grande número de alunos (embora o discurso fosse de educação popular), mas sim, levar o conhecimento a alguns poucos privilegiados, mantendo-os entre as paredes das salas de aulas, submetidos ao olhar vigilante do professor o tempo necessário para terem seu caráter domado e seu comportamento convenientemente formado, até que fossem transformados em cidadãos e trabalhadores educados, de bom caráter e lhes fossem atribuídas qualidades servis, mostrando-se preparados para ocupar cargos de mando e no mercado de trabalho que surgia.

De acordo com Sá (2007, p. 125), o Palácio da Instrução representou, à época, um contraste no cenário urbano da capital, tendo em vista que nesse período Cuiabá era "composta de casa feitas de abobe, constituindo um exemplo de como deveria ser a cidade moderna", conforme se vê na 
imagem que se segue, na qual o referido prédio está localizado ao lado da Igreja Matriz (canto esquerdo da foto).

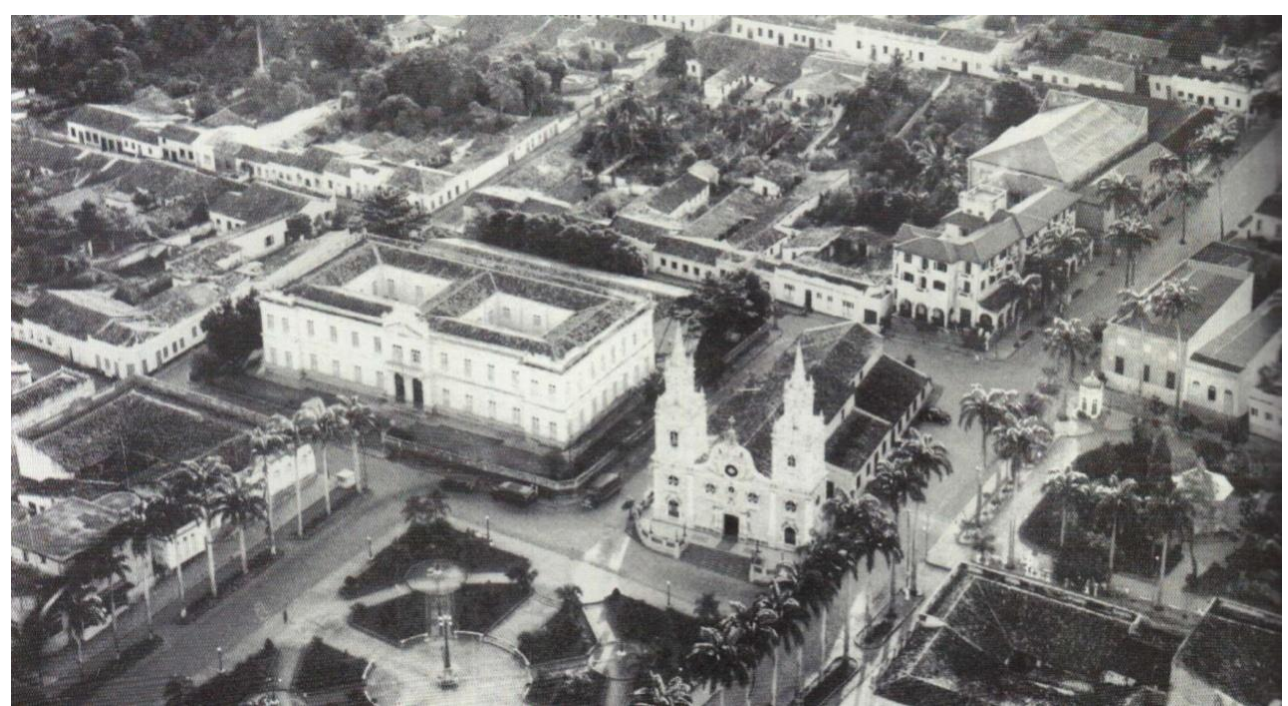

Ilustração: 01: Palácio da Instrução, Cuiabá - MT, década de 1950.

Fonte: SIQUEIRA, 2002, p. 186.

O prédio do Palácio da Instrução abrigou a Escola Normal e, de acordo com as normativas de 1910 que regiam a instituição, haveria, anexa a ela, um grupo escolar "sob a denominação de Escola Modelo" (REGULAMENTO, 1910, p. 169). Com relação a Escola Modelo, Reis (2005, p. 128) esclarece que essa "foi uma instituição de ensino primário que serviu de 'oficina pedagógica' para os alunos da escola normal, além de ser o 'modelo', para demais escolas primárias do estado."

As aulas da Escola Modelo tinham como objetivo promover o exercício prático dos futuros professores durante o estágio no curso, supervisionados pelo diretor da Escola Normal. "A Escola Modelo é destinada à prática pedagógica dos alunos dos $2^{\circ}$ e $3^{\circ}$ anos do curso Normal e servirá de modelo para todos os grupos escolares e escolas isoladas do Estado." A Escola Modelo seguia as disposições do Regulamento da Instrução Pública de 1910 e o regime interno dos grupos escolares (REGULAMENTO, 1910, p. 169), e recebeu o nome de Barão de Melgaço. Era composta por:

[...] 10 classes e funcionava inicialmente num regime de cinco anos. Compreendia os cursos elementar (4 anos) e complementar ( 1 ano). Era dividido em seções masculinas e femininas, e as mulheres deveriam lecionar somente para as primeiras séries do ensino primário. Só a partir de 1922 é que a Escola Modelo passou a ter a mesma estrutura do Grupo Escolar com a redução do seu curso para apenas quatro anos. (REIS, 2005, p. 130).

Em 1913, a matrícula no Grupo Escolar do $1^{\circ}$ distrito da Capital ou Escola Modelo, de acordo com Marques (REGULAMENTO, 1913, p. 40), ficou em torno de 383 alunos, divididos em 195, na seção masculina, e, 188, na feminina. Entretanto, a frequência média não passou de "235 alunos, dos quais 115 pertencem a seção masculina e 120 a seção feminina dando para a freqüência uma porcentagem $85 \%$ em ambas as seções."

Coube a Leowigildo de Mello a direção do Grupo Escolar do $1^{\circ}$ Distrito (Palácio da Instrução), o Grupo Escolar Barão de Melgaço, e a Gustavo Kuhlmann a do Grupo Escolar do $2^{\circ}$ distrito, o Grupo Escolar Senador Azeredo. O Grupo Escolar Senador Azeredo, inaugurado em 10 de setembro de 1910, foi erigido no bairro do Porto, à Rua Senador Azeredo, esquina com a Rua 13 de Junho, constituindo um dos melhores edifícios do estado (RELATÓRIO, 1943). "A construção do Grupo Escolar Senador Azeredo, localizado no $2^{\circ}$ distrito, embora apresentasse uma edificação mais simples, se comparada 
à do Palácio da Instrução, ainda impunha uma arquitetura não comum à capital matogrossense" (SÁ, 2007, p. 125).

A proposta pedagógica para os grupos escolares mato-grossenses teve ensino de Educação Moral e Cívica incluído em sua grade curricular, por entenderam que,

[...] o ensinamento dos deveres de cada qual para consigo, para com os seus, para com a Sociedade e para com a Patria. E isto se faz pelo estimulo do patriotismo, ministrando ao alumno o conhecimento dos heroes verdadeiros, daquelles que, por seus meritos e virtudes cívicos, dignos se fizeram do nosso amor e do nosso respeito. (RELATÓRIO, 1910, p. 10).

O programa de ensino do estabelecimento abrangia também uma educação voltada para o aprendizado das seguintes matérias ou disciplinas:

[...] uma uniformidade perfeita em suas aulas e impossibilita completamente o desenvolvimento maior de uns em prejuízo de outros conhecimentos. Os programas da primeira a' quarta classe, contem, de accordo com o desenvolvimento particular de cada classe, as seguintes materias: Leitura - linguagem oral e escripta - arithmetica - geographia historia patria - scienciasphysicas e naturaes e hygiene - educação moral e civica - geometria - musica - desenho - gymnastica e trabalhos manuaes. (RELATÓRIO, 1910, p. 10).

Com relação à educação física, essa disciplina era considerada necessária, pois acreditava-se que a evolução dos aspectos psicológicos do homem teriam estreita relação com sua vida orgânica: "Não seria portanto natural que a escola cuida-se dos educados moral e intelectualmente, desprezando a educação physica. Já de ha muito se conhece o vulgar - mens sana incorpore sano." Por isso, a importância de se articular o desenvolvimento psicológico com o desenvolvimento físico (RELATÓRIO, 1910, p. 10). As disciplinas aplicadas no Grupo Escolar eram assim distribuídas na grade horária:

\begin{tabular}{|c|c|c|c|}
\hline \multirow{3}{*}{$\begin{array}{c}\text { Divisão do } \\
\text { Tempo } \\
\text { Escolar }\end{array}$} & \multicolumn{3}{|c|}{$1^{\circ}$ ANO DO GRUPO ESCOLAR } \\
\hline & \multicolumn{3}{|c|}{ Dias da Semana } \\
\hline & Segunda & Terça & Sábado \\
\hline $12: 00$ a $12: 10$ & \multicolumn{3}{|l|}{ Chamada e canto } \\
\hline $12: 10$ a $12: 30$ & $\begin{array}{l}\text { Aritmética, Cálculo, Números e Cartas } \\
\text { Parker }\end{array}$ & $\begin{array}{l}\text { Geometria, Estudos } \\
\text { métrico. }\end{array}$ & nas, Sist. \\
\hline $12: 30$ a $13: 00$ & \multicolumn{3}{|l|}{ Leitura Seção A; ocupação Seção B e C. } \\
\hline 13:00 a 13:25 & \multicolumn{3}{|l|}{ Leitura Seção B; ocupação Seção A e C. } \\
\hline $13: 25$ a $13: 35$ & \multicolumn{3}{|l|}{ Exercício Callisthenicos } \\
\hline 13:35 a 14:00 & \multicolumn{3}{|l|}{ Leitura Seção C; ocupação Seção A e B. } \\
\hline $14: 00$ a $14: 20$ & \multicolumn{3}{|l|}{ Calligraphia } \\
\hline $14: 20$ a $15: 00$ & \multicolumn{3}{|c|}{$\begin{aligned} \text { RECREIO } \\
\end{aligned}$} \\
\hline 15:00 a 15:20 & \multicolumn{3}{|c|}{\begin{tabular}{l|l} 
Geografia, História e Instrução Cívica & ScienciasPhysicas e NaturaesHygiene \\
\end{tabular}} \\
\hline $15: 20$ a $15: 40$ & \multicolumn{3}{|c|}{ Leitura Seção A; ocupação Seção B e C. } \\
\hline $15: 40$ a $15: 55$ & \multicolumn{3}{|l|}{ Leitura ou cópia de Parker. } \\
\hline 15:55 a 16:15 & \multicolumn{3}{|l|}{ Leitura Seção B; ocupação Seção A e C. } \\
\hline $16: 15$ a $16: 30$ & \multicolumn{3}{|l|}{ Leitura Seção C; ocupação Seção A e B. } \\
\hline $16: 30$ a $16: 35$ & \multicolumn{3}{|l|}{ Marcha e Canto } \\
\hline 16:35 a 17:00 & \multicolumn{3}{|c|}{ Desenho e jogo gymnasticos e trabalho manual canto e declamação } \\
\hline
\end{tabular}




\begin{tabular}{|c|c|c|c|c|c|c|}
\hline \multirow{3}{*}{$\begin{array}{c}\text { Divisão do } \\
\text { Tempo } \\
\text { Escolar }\end{array}$} & \multicolumn{6}{|c|}{$2^{\circ}$ ANO DO GRUPO ESCOLAR } \\
\hline & \multicolumn{6}{|c|}{ Dias da Semana } \\
\hline & Segunda & Quarta & Sexta & Terça & Quinta & Sábado \\
\hline 12:00 a $12: 10$ & \multicolumn{6}{|c|}{ Chamada e canto } \\
\hline $12: 10$ a $12: 35$ & \multicolumn{3}{|c|}{ Aritmética } & \multicolumn{3}{|c|}{ Geometria } \\
\hline $12: 35$ a $13: 15$ & \multicolumn{6}{|c|}{ Leitura expressiva } \\
\hline $13: 15$ a $13: 45$ & \multicolumn{3}{|c|}{ Geographia e Cosmographia } & \multicolumn{3}{|c|}{ História Pátria } \\
\hline $13: 45$ a $14: 00$ & \multicolumn{6}{|c|}{ Calligraphia } \\
\hline $14: 00$ a $14: 20$ & \multicolumn{3}{|c|}{ Leitura e cópia Parker } & \multicolumn{3}{|c|}{ Gymnastica } \\
\hline $14: 20$ a $15: 00$ & \multicolumn{6}{|c|}{ RECREIO } \\
\hline 15:00 a 15:30 & \multicolumn{6}{|c|}{ Leitura suplementar } \\
\hline $15: 30$ a $15: 50$ & \multicolumn{6}{|c|}{ ScienciasPhysicas, Naturaes. Moral e Cívica } \\
\hline $15: 50$ a $16: 10$ & \multicolumn{6}{|c|}{ Linguagem oral } \\
\hline $16: 10$ a $16: 35$ & \multicolumn{6}{|c|}{ Linguagem escripta } \\
\hline 16:35 a $17: 00$ & Desenho e tr & & & Gymnast & canto e dec & ção \\
\hline \multirow{3}{*}{$\begin{array}{c}\text { Divisão do } \\
\text { Tempo } \\
\text { Escolar } \\
\end{array}$} & \multicolumn{6}{|c|}{$3^{\circ}$ e $4^{\circ}$ ANO DO GRUPO ESCOLAR } \\
\hline & \multicolumn{6}{|c|}{$\begin{array}{c}\text { Dias da Semana } \\
\end{array}$} \\
\hline & Segunda & Quarta & Sexta & Terça & Quinta & Sábado \\
\hline $12: 00$ a $12: 10$ & \multicolumn{6}{|c|}{ Chamada e canto } \\
\hline $12: 10$ a $12: 45$ & \multicolumn{3}{|c|}{ Aritmética } & \multicolumn{3}{|c|}{ Geometria } \\
\hline $12: 45$ a $13: 25$ & \multicolumn{3}{|c|}{ Linguagem oral } & \multicolumn{3}{|c|}{ Geographia e Cosmographia } \\
\hline $13: 25$ a $13: 50$ & \multicolumn{3}{|c|}{ Geog e Cosmologia } & \multicolumn{3}{|c|}{ História Pátria } \\
\hline $13: 50$ a $14: 20$ & \multicolumn{6}{|c|}{ Linguagem escripta } \\
\hline 14:20 a 15:00 & \multicolumn{6}{|c|}{$\begin{array}{ll} & \text { RECREIO } \\
\end{array}$} \\
\hline 15:00 a 15:30 & \multicolumn{6}{|c|}{ Leitura suplementar } \\
\hline $15: 30$ a $15: 55$ & \multicolumn{3}{|c|}{ História Pátria } & Sciencias & sicas e Nat & Sygiene \\
\hline $15: 55$ a $16: 15$ & Calligraphia & & & & & \\
\hline $16: 15$ a $16: 40$ & Desenho, jog & vercícios $\mathrm{m}$ & & Problema & esenho e $\mathrm{p}$ & mas \\
\hline $16: 40$ a $17: 00$ & Gymnastica, & & & Educaçãc & ral e Cívic & Música \\
\hline
\end{tabular}

Quadro 01: Horário de aulas do Grupo Escolar

Fonte: RELATÓRIO, 1910, p. 117.

A partir das informações expostas no quadro 01, infere-se que o tempo no $1^{\circ}$ ano do grupo escolar se apresentava extremamente divido, sendo mínimo o intervalo entre uma disciplina e outra (intervalo de 10 a 30 minutos aulas). Do $2^{\circ}$ ao $4^{\circ}$ anos, os intervalos entre as elas passaram a ser menores, variando de 15 a 45 minutos aulas. Os exercícios militares eram reservados ao sexo masculino e substituídos, na seção feminina, por aulas de prendas domésticas. As disciplinas de leitura, linguagem e aritmética e geometria permeavam os quatro anos do curso primário do grupo escolar.

A distribuição das disciplinas seguia alguns preceitos pedagógicos que contribuíam para sua ordem e desenvolvimento. O preceito inicial tinha como condicionante a maior complexidade das disciplinas e exigia atenção especial do aluno, como as matérias relacionadas com a matemática, visto que a "aritmética, cálculo e geometria, ocupavam, em todas as séries, o primeiro horário, com uma duração que variava de $20\left(1^{\circ}\right.$ e $2^{\circ}$ anos) a 35 minutos ( $3^{\circ}$ e $4^{\circ}$ anos)."

Eram reservadas para o último horário do primeiro ano, as disciplinas de desenho, jogos, ginástica, trabalho manual, canto e declamação. Elas, com exceção de jogos, também se encontravam presentes no último horário do segundo ano. Para o último horário do terceiro e do quarto anos, nas segundas, quartas e sextas-feiras, ginástica, e às terças, quintas e sábados, música e educação moral e cívica. Como segundo preceito a ser seguido, estabeleceu-se "intercalar, quando possível, exercícios de fácil execução entre as outras disciplinas para descanso do aluno". Por isso distribuíram as aulas intercalando as disciplinas que exigiam mais "esforço" do aluno com outra que requeria menor grau de dificuldade (MELLO; KUHLMANN apud SÁ, 2007 p. 139-140). 
Com relação à distribuição do tempo escolar, Mello (RELATÓRIO, 1910, p. 6) esclarece que esse se constituiu em tarefa de maior complexidade na escola. Segundo o mesmo, um bom horário deveria ter como princípios:

a) occupar toda a classe; b) proporcionar a duração dos exercícios a edade e ao desenvolvimento physico e intellectual dos alumnos; c) abranger o programma completo, destinado a cada materia o tempo exigido pela maior ou menor difficuldade com outros menos difficeis.

A organização da Instrução Pública mato-grossense sofreu mudanças no final da década de 1920, isso porque entrou em vigor, por meio do Decreto $\mathrm{n}^{\circ} 759$, de 22 de abril de 1927, o novo Regulamento da Instrução Primária. Com essa nova diretiva, o ensino ficou distribuído entre as seguintes categorias: escolas isoladas rurais; escolas isoladas urbanas; escolas isoladas noturnas; escolas reunidas e grupos escolares.

Os grupos escolares seriam constituídos de, no mínimo, 8 classes e instalados nas localidades com, pelo menos, 250 crianças em idade escolar, residindo num raio de 2 quilômetros. Para as classes dos grupos escolares, seriam destinados professores com "1um ano de exercício efetivo em escola urbana; 2- dois anos em escola rural; 3- e por professores normalistas, com três anos de exercício interino" (REGULAMENTO, 1927, p. 172).

A prerrogativa do Regulamento determinava que a classe do grupo escolar cuja matrícula excedesse a 45 alunos, seria "[...] desdobrada, dando-se à nova classe que resultar do desdobramento, provimento interino, sendo nomeados os normalistas que tiverem maior nota no cômputo geral das obtidas no curso das escolas normais." (REGULAMENTO, 1927, p. 172). Diferentemente dessa organização as escolas isoladas eram multiseriada.

\section{As escolas isoladas em Mato Grosso}

No inicio dos anos de 1900, além dos grupos escolares, outra modalidade presente no cenário educacional de Mato Grosso eram as Escolas Isoladas. As escolas isoladas se caracterizaram como um modelo escolar que produzia poucos resultados educacionais, na concepção dos governantes mato-grossenses. Tinham o objetivo de ministrar a instrução primária rudimentar e se localizavam a mais de 3 quilômetros da sede municipal (MENSAGEM, 1927). Essas instituições funcionavam, às vezes, na casa do professor ou em um prédio alugado, sendo instituições unidocentes e compostas por classes mistas. Sobre a escola isolada em Mato Grosso, Reis (2011, p. 21) elucida que:

[...] foram responsáveis pelo atendimento e pela escolarização da maioria da população mato-grossense. Além disso, elas concorriam, e muitas vezes superavam os Grupos Escolares em número de Escolas e Alunos, graças à facilidade de sua criação e implantação em regiões de difícil acesso e localização espalhadas pelo estado de Mato Grosso.

As escolas isoladas, como o próprio nome indica, se localizavam distantes dos centros urbanos, se caracterizam como um modelo que não produzia resultados educacionais. Tinham o objetivo de ministrar a instrução primária rudimentar, se localizavam a mais de 3 quilômetros da sede municipal.

Sá e Sá (2011, p.50) explicam que este modelo escolar predominava em Mato Grosso, porque o estado raramente gastava com construção de prédios e contratação de um número maior de professores. Essas instituições funcionavam na "casa do professor ou outra residência alugada, entendidas como modalidade escolar na qual o professor ensinava 
sozinho a uma turma de até 60 alunos distribuídos em graus diferenciados de desenvolvimento [...]". A partir de 1920, a nomenclatura escola isolada começou a ser empregada com mais frequência nas mensagens dos governantes de Mato Grosso e nos demais documentos oficiais. As escolas isoladas continuavam a superar numericamente os grupos escolares, pois entre 1913 e 1921 a tabela numérica apontava um crescimento expressivo das escolas isoladas estaduais:

\section{Tabela 01}

Unidades escolares em Mato Grosso

\begin{tabular}{c|c|c}
\hline Ano & Escolas Isoladas & Grupos Escolares \\
\hline 1913 & 123 unidades & 05 unidades \\
\hline 1914 & 126 unidades & 05 unidades \\
\hline 1916 & 144 unidades & 05 unidades \\
\hline 1919 & 164 unidades & 05 unidades \\
\hline 1920 & 235 unidades & 05 unidades \\
\hline 1921 & 241 unidades & 05 unidades \\
\hline
\end{tabular}

Fonte: ALVES, 1998.

No ano 1923, o presidente de Mato Grosso, Pedro Celestino da Costa, em mensagem a Assembleia Legislativa do Estado, deixar transparecer que os problemas educacionais com as instituições escolares localizadas nas áreas isoladas e/ou rurais, considerada de ensino ineficiente ou quase nulo, eram em maiores proporção dos que os enfrentados em outros Estados brasileiros. Ele explica que em Mato Grosso, "[...] as difficuldades a superar são maiores, devido a disseminação da população infantil por enormes superfícies de modo que se multipliquem as escolas, não poderão ellas servir a todos quantos careçam de instrucção (MENSAGEM, 1923, p.45).

Por motivos atrelados ao seu isolamento geográfico, as escolas isoladas, ficavam "entregues aos parcos recursos didáticos, pedagógicos e financeiros [...]" (PAES, 2011, p. 65). Souza (2008, p.124) acrescenta outras dificuldades pelas quais as escolas isoladas tinham que enfrentar, como: "a precariedade dos edifícios que abrigavam estas escolas, carência de mobiliário, de material didático, dificuldade de emprego dos métodos modernos de ensino e de cumprimento integral dos programas escolares, dificuldades de provimentos de professores nas escolas isoladas, baixos salários dos professores e precárias condições de trabalho". Assim, como os Grupos Escolares, as escolas isoladas tiveram um papel importante para educação primária em Mato Grosso, proporcionando ao alunado mato-grossense, das localidades afastadas do estado acesso à educação primária.

Percebe-se que tanto os grupos escolares quanto as escolas isoladas foram importantes para o surgimento de um novo modelo escolar em Mato Grosso, pois dos grupos escolares, as escolas reunidas possuem como similaridade a organização estrutural e pedagógica. Com relação as escolas isoladas, sem estas não se poderia criar escolas reunidas, pois necessitava-se de 3 ou mais dessas escolas isoladas, agrupadas em um só prédio e assim se compor uma Escola Reunidas. 


\title{
3 Criação e funcionamento das Escolas Reunida de Mato Grosso
}

A educação primária em Mato Grosso, na década de 1920, era ministrada através de grupos escolares e escolas isoladas, alvo de preocupação por parte dos governantes. Em mensagem à Assembleia Legislativa mato-grossense, Pedro Celestino Corrêa da Costa, então presidente do estado, expressou suas inquietações, dizendo: "A instrucção que deve ser ministrada pelas escolas abrange noções de conhecimentos necessários à formação de cidadãos aptos à vida pratica e à colaboração para o progresso da sociedade em que vive." (MENSAGEM, 1923, p. 34).

Pedro Celestino (MENSAGEM, 1923, p. 34) ressaltou também que os governantes não poderiam cometer falhas quando o assunto envolvia a instrução de seu povo, pois se os problemas educacionais não fossem resolvidos pelos estados brasileiros, permaneceria "[...] apparente a prosperidade do Brasil, limitada como se acha às grandes cidades, ao passo que nas populações ruraes a ignorancia e o analphabetismo conservam a grande maioria dos nossos patrícios no desconforto e na miseria orgânica".

Costa ressaltou ainda a especificidade de Mato Grosso e seus problemas com as escolas isoladas, pois as "[...] difficuldades a superar são maiores, devido á disseminação da população infantil por enormes superfícies de modo que se multipliquem as escolas, não poderão ellas servir a todos quantos careçam de instrucção." (MENSAGEM, 1923, p. 45). Segundo ele:

\begin{abstract}
A importancia orçamentária despendida com as escolas isoladas esparsas pelas localidades dos municípios não correspondem aos resultados alcançados. Mal providas em geral, taes escolas funccionam à revelia da fiscalização dos respectivos inspectores e sem proveito algum de ensino. Tendo por isso, supprimido algumas delas e deixado de prover outras cuja a inutilidade tem sido constatada pela inspecção. (MENSAGEM, 1923, p. 45).
\end{abstract}

Em 1926, ao assumir a presidência do estado, Mário Corrêa da Costa defendeu a ideia de que Mato Grosso deveria reorganizar a instrução pública. Para isso, em 1926, formou uma comissão para a elaboração do novo Regulamento da Instrução Pública estadual, composta pelo Dr. Cesário Alves Corrêa, diretor geral da instrução pública, Jayme Joaquim de Carvalho, Isác Povoas, Júlio Müller, Franklin Cassiano da Silva, Philogonio Corrêa, Fernando Leite Campos, Nilo Póvoas, Alcindo de Camargo e Rubens de Carvalho, o último, professor paulista contratado pelo governo para atuar na instrução pública.

O novo Regulamento manteve os grupos escolares, dividiu as escolas isoladas em três categorias: urbanas, rurais e noturnas, implantada pelo Regulamento de 1927 e criou as escolas reunidas, "quando num raio de dois quilômetros, funcionarem três ou mais escolas isoladas, num raio de $2 \mathrm{~km}$, com frequiência total mínima de 80 alunos, o governo poderá reuni-las num só estabelecimento" (REGULAMENTO, 1927, Art. 19, p. 166).

As escolas reunidas teriam o máximo de 7 e mínimo de 3 classes, obedecendo a quantidade não inferior a 15 e nunca superior a 45 alunos por classe. Diferentemente dos grupos escolares, onde havia uma ou mais classes para cada ano escolar, nas escolas reunidas era permitida a fusão numa só classe de dois ou mais anos do curso, ou a formação de classes mistas, quando o número de alunos matriculados fosse insuficiente para a separação por sexo e graduação de curso em salas distintas.

As classes que obtivessem matrícula e frequência inferior a 15 alunos, num período de três meses consecutivos, seriam extintas. Importante salientar que, nas escolas reunidas onde estivesse funcionando, no período de um ano, uma média frequente de oito classes, 
elas seriam transformadas em grupos escolares (REGULAMENTO, Art. 28, 1927). A documentação indicou um constante movimento de mudança de categoria escolar, uma vez que as escolas reunidas poderiam ser transformadas em grupos escolares pelo aumento das classes, ou o quando algum grupo escolar não funcionasse com o número de alunos prescrito no Regulamento de 1927, seria rebaixado a escolas reunidas, como no caso do Grupo Escolar de Ponta-Porã.

Sob a justificativa de contenção de gastos, o diretor geral da instrução pública de Mato Grosso, Franklin Cassiano da Silva, afirmou que "não podia permanecer-me indiferente diante à despesa que vinha fazendo o Estado para manter um grupo sem eficiência no ensino e cuja matrícula era de 146 alunos, inferior, portanto, a de todas as escolas reunidas existentes no Estado." (RELATÓRIO, 1931, p. 8), por isso, seria rentável transformar o Grupo Escolar de Ponta-Porã em escolas reunidas. O prefeito da cidade protestou contra essa medida, talvez porque a cidade perderia o status fechando um estabelecimento de ensino que era símbolo de progresso.

Percebe-se que somente o primeiro ano (seções masculinas e femininas) possuía número suficiente de alunos determinado pelo Regulamento da Instrução Pública de 1927 (o mínimo de 15 e o máximo de 45 alunos por sala) e as demais seções possuíam menos de 15 matriculados. O mesmo Diretor Geral da Instrução Pública, para complementar suas alegações de transformação do Grupo Escolar de Ponta-Porã em escolas reunidas, enfatizou: "Nenhum tipo de escola oferece, por isso, maior vantagem para o ensino que o das escolas reunidas." Continuou,

Com a mesma organização dos grupos escolares, os mesmos métodos de ensino, a sua única diferença é que o diretor do grupo recebe vencimento fixo de $720 \$ 000$ mensais, quer aumente, quer diminua o número de matrícula, e o quadro do corpo docente é sempre fixo, constando de 8 professores. Nas escolas reunidas, o diretor não tem vencimento fixo do cargo, ganha como professor e terá seus vencimentos aumentados conforme o seu esforço, a sua dedicação e a confiança que desperta à população da localidade em que estiver localizada a escola. (RELATÓRIO, 1931, p. 9).

Por motivo similar, o Grupo Escolar de Miranda passou a Escolas Reunidas Caetano Pinto, localizadas no sul de Mato Grosso. O grupo de Miranda funcionava em edifício alugado pela prefeitura, com amplas instalações, "arejado, de bela aparência e bom estado. Com a exoneração do seu diretor (filho do lugar), exigiram a mudança do Grupo, o que foi feito, para um prédio mal situado e sem as acomodações necessárias." (RELATÓRIO, 1931, p. 13).

Esforços foram despendidos junto ao executivo municipal a fim de que os problemas com o novo local de instalação da escola fossem sanados. Entretanto, não era somente o prédio que apresentava necessidade de reparos, outros problemas se apresentavam, como o reduzido número de alunos (RELATÓRIO, 1931).

Sobre essa questão, o Art. 34 do Regulamento de 1927 determinava que os grupos escolares deveriam ser criados quando, pelo menos num raio de 2 quilômetros, existissem 250 crianças em idade escolar para frequentar as aulas, fato que não ocorria no Grupo Escolar de Miranda, pois sua frequência de alunos não chegava a 100 crianças.

O Grupo Escolar de Miranda, criado pela Resolução $n^{\circ} 857$, de 12 de junho de 1922, passou à categoria de escolas reunidas em 1931, por meio do Decreto Orçamentário $\mathrm{n}^{\circ}$ 77, de 20 de junho. Em 1939, o número de estabelecimentos escolares em Mato Grosso chegou ao montante de 265, distribuídas em diversos municípios do estado: 


\begin{tabular}{|l|c|}
\hline \multicolumn{2}{|c|}{$\begin{array}{c}\text { NÚMERO DE ESCOLAS PRIMÁRIA MATO- } \\
\text { GROSSENSES EM 1939 }\end{array}$} \\
\hline Denominação da escola & Quantidade \\
\hline Grupo Escolar & 13 \\
\hline Escolas Reunidas & 22 \\
\hline Escolas Isoladas Urbanas & 19 \\
\hline Escolas Distritais & 52 \\
\hline Escolas Regimentais & 15 \\
\hline Escolas Rurais & 144 \\
\hline Total de escolas & 265 \\
\hline
\end{tabular}

Quadro 02: número de escolas primárias mato-grossenses

Fonte: RELATÓRIO DO INTERVENTOR DO ESTADO DE MATO GROSSO, 1939.

Percebe-se que o número de escolas reunidas é quase o dobro do número de grupos escolares e que as escolas rurais superavam em grande quantidade todas as demais modalidades de escolas. O mapa abaixo mostra a localização dessas escolas.

Outra característica própria das escolas reunidas era quanto à administração escolar. Em contraposição aos grupos escolares, sua direção ficaria a cargo de um professor nomeado pelo governo, com regência indispensável de classe. Este teria vencimentos iguais aos demais professores das escolas reunidas, mas seria acrescida uma "gratificação mensal de $30 \$ 000$ (trinta mil réis) por classe, não computada a sua." (REGULAMENTO, 1927, p. 166).

Para o funcionamento das escolas reunidas era necessário apenas "um porteiro servente, com o ordenado arbitrado pelo governo", sendo contratado e/ou dispensado pelo Secretário do Interior. A ele caberiam deveres e obrigações dispensados aos porteiros e serventes dos grupos escolares, acumulando, nessa medida, dupla função (REGULAMENTO, 1927, p. 183). O regimento interno das escolas reunidas seguiu as mesmas diretrizes dos grupos escolares, ficando sua organização sob a responsabilidade da Diretoria Geral da Instrução, desde que estivesse em consonância com as aspirações do governo estadual.

Quando o prédio das escolas reunidas apresentasse limitações para atender a demanda de alunos, o diretor poderia determinar seu o funcionamento em dois turnos. $\mathrm{O}$ diretor ministrava aulas somente em um período, mas teria que permanecer na escola por dois turnos e, para isso, receberia "além dos seus vencimentos, uma gratificação de $50 \$ 000$ (cinquenta mil réis), correspondente à direção do segundo turno.” (REGULAMENTO, 1927, p. 171).

Percebe-se que as fontes documentais trazem diferentes informações sobre os valores da gratificação recebida pelos diretores das escolas reunidas. Conforme o Regulamento da Instrução Publica de Mato Grosso de 1927, Art. 26, receberiam uma gratificação de $30 \$ 000$, pela regência indispensável de classe em um período (matutino ou vespertino); no mesmo documento. Art. 57, quando estes permanecessem na escola nos dois turnos (matutino e vespertino), receberiam a gratificação de 50\$000; a terceira menção de gratificação se encontra no relatório do diretor do Grupo Escolar de Poconé Waldomiro Campos, do ano de 1916. A gratificação pela primeira situação seria de 60\$000. Corroborando com Campos, o Diretor Geral da Instrução Pública Primária de Mato Grosso, Frankiln Cassiano da Silva, em 1931, ressaltava que o diretor receberia pela mesma situação uma gratificação de $60 \$ 000$.

Não se sabe ao certo se foi erro de grafia, ou se os valores descritos no Regulamento representavam uma intenção de conter gastos do governo com o pagamento de gratificações aos diretores das escolas reunidas. $\mathrm{O}$ que se percebe é uma predominância da menção do valor da gratificação em $60 \$ 000$, em outras fontes documentais. 
Os professores efetivos que tivessem suas classes extintas por motivo do fechamento poderiam escolher, "dentro de 30 dias e entre as escolas vagas de igual categoria, a que lhes convier", caso não fizesse essa escolha, seriam "aproveitados, dentro de 60 dias, a contar da supressão, para uma escola mais próxima e de igual categoria, de preferência dentro do município." (REGULAMENTO, 1927, p. 169). A escola reunida que fosse transformada em grupo escolar ofertaria ainda a opção de seus docentes se integrarem ao quadro de professores adjuntos. Essas instituições teriam o provimento de vagas para efetivação do quadro de professores por meio de concurso público.

Para tanto, o docente teria ter dois anos de exercício do magistério em escolas rurais, ou um ano como professor em escolas urbanas, podendo também se inscrever em concurso "professores normalistas que contarem quatro anos de magistério público ou particular." (REGULAMENTO, 1927, p. 172). O concurso era composto de dois momentos: uma prova escrita e outra prática. O Diretor Geral da Instrução Pública instituiria uma comissão, composta por quatro membros indicados pelo governo para analisar o desempenho dos candidatos, sendo dela seu presidente.

Com relação ao ano letivo das escolas primárias mato-grossenses, este deveria começar no dia $1^{\circ}$ de março e terminar aos 30 de novembro, para todos os estabelecimentos de ensino primário. Haveria suspensão das aulas somente "aos domingos, nos dias feriados nacionais e estaduais e nos dias que decorrem de 15 a 30 de junho" e nos dias decorrentes de férias. "Fora destes casos, somente serão suspensos os trabalhos excepcionalmente, por determinação do governo do Estado.” (REGULAMENTO, 1927, p. 179).

O modelo de escola reunida mato-grossenses foi implantado com a intenção de que, depois de instituídas e consolidadas como instituições educacionais, se transformassem em grupos escolares e, dessa forma, alavancassem qualitativamente a educação. As privações apresentadas pelas escolas reunidas de Mato Grosso se assemelhavam às dos grupos escolares, ficando por vezes, difícil determinar diferenças entre elas. Em 1930, Mato Grosso contava com 4escolas reunidas implantadas nos municípios de Livramento, de Santo Antônio do Rio Abaixo, de Santana do Paranaíba e de Bela Vista. Entretanto, havia somente uma em funcionamento, a de Santo Antônio do Rio Abaixo (RELATÓRIO, 1931, p. 6). Nesse cenário, foi criada a Escola Reunida de Santo Antônio do Rio Abaixo, em 4 de março de 1930, através da junção de três escolas públicas isoladas de ambos os sexos, que funcionavam na região.

O Diretor Geral da Instrução Pública de Mato Grosso ressalta que essa era a única escola Reunida instalada no Estado e que as de Várzea Grande e Livramento teriam suas instalações efetivadas naquele mesmo ano, 1931. (SILVA, 1931, p. 6).

As Escolas Reunidas de Santo Antônio do Rio Abaixo, segundo o Diretor Brasil (1930, p. 18), era quase que desprovida de mobiliário e contava somente com "8 bancos de madeira, 8 carteiras, 3 mesas e 4 quadros negros". O mobiliário não se apresentava apto a compor uma instituição escolar. Seu descontentamento tinha precedente, já que por lei o governo teria que prover o necessário para melhor funcionamento das escolas públicas, como preconizava o Art. 259 do regulamento da instrução pública mato-grossense de 1927 que regia essa prerrogativa. Nesse artigo encontra-se a seguinte normativa: "O governo fornecerá a todas as escolas públicas do Estado, o mobiliário e o material necessário ao seu eficiente funcionamento". (REGULAMENTO, 1927, p. 166).

O Professor Américo Pinto Brasil (1930, p.19), diretor das Escolas Reunidas de Santo Antônio do Rio Abaixo, explica sobre essa questão que apesar de seus "reiterados pedidos para uniformizar o estabelecimento do necessário nada pude conseguir por se encontra aquele almoxarifado desprovido de tudo." Acrescenta que "há no Estabelecimento diversos bancos de madeira e mesas tomados por empréstimos a particulares e mais um quadro negro [...]" cedida por um coronel da cidade. 
Percebe-se que implantação das Escolas Reunidas de Santo Antonio de Rio Abaixo, atendia as necessidades dos governo de Mato Grosso de contenção de gastos, pois para sua criação foram suprimidas 3 escolas isoladas daquela localidade. Os alunos das três escolas isoladas reunidas passaram a ocupar somente um prédio, alugado que, pela descrição do Diretor Brasil, não tinha condições para abrigar uma instituição escolar.

\section{Considerações finais:}

Diante das reflexões até aqui apresentadas, pode-se concluir que os grupos escolares apresentavam inúmeros problemas estruturais, sendo que a maioria dos prédios no estado não atendia a proposta inicial implantada por Leowigildo Martins de Mello e Gustavo Kuhmann, professores paulista, contratados pelos governantes mato-grossenses para a implantação da proposta desse modelo de instituição educacional. Os prédios não eram construções grandes, sendo por vezes alugados e adaptados para o cotidiano escolar. Por isso, não havia significativas mudanças na estrutura organizacional e pedagógica, quando um grupo escolar, perdia essa classificação e passava a pertencer à categoria de escolas reunidas, de menor custeio por parte do estado, similar à organização dos grupos escolares e que poderiam ser implantadas em localidades distantes dos centros urbanos.

Percebe-se que ao se intensificar a abertura de estradas e a circulação de mercadorias no comércio, os governantes buscavam o desenvolvimento dos municípios produtores de grãos no interior do estado. Esse fato sugere que ao promover o desenvolvimento de pequenas cidades e vilarejos, locais em que as escolas reunidas eram mais frequentes, aumentava-se o contingente de pessoas e de alunos nas escolas. Assim, com o desenvolvimento da cidade e a efetivação de oito classes anual (REGULAMENTO, 1927), as escolas reunidas logo eram transformadas em grupos escolares. Esse fato pode ser comprovado ao se verificar a redução do número de escolas reunidas na década de 1950.

Diante do percurso até aqui apresentado, não se pretende esgotar o assunto relacionado às escolas reunidas de Mato Grosso, espera-se ter contribuído para o estudo sobre a temática das instituições escolares primárias mato-grossenses, deixando pistas para que novas pesquisas possam ser desenvolvidas a partir deste trabalho. Por meio de fontes documentais e depoimentos orais, buscou-se reconstituir fatos ocorridos no passado e relativos à temática das instituições escolares, porque "o vivido é irrecuperável, que a história opera sempre em nível de reconstrução e que esta reconstrução nunca é perfeita." (VIDAL, 1990, p. 82).

\section{Referências}

ARAÚJO, José Carlos Souza. Os Grupos Escolares em Minas Gerais: a reforma João Pinheiro (1906). Anais... do VI Congresso Luso-Brasileiro de História da Educação. Percursos e Desafios da Pesquisa e do Ensino de História da Educação: Uberlândia, Minas Gerais - $\quad$ Brasil, $2006 . \quad$ Disponível em: $\langle$ http://www.faced.ufu.br/colubhe06/anais/arquivos/19JoseCarlosSousa.pdf $>$. Acesso: $01 / 03 / 2012$.

ALVES, Laci Maria Araújo. Nas trilhas do ensino (1910-1946). Cuiabá: EdUFMT, 1998.

BRASIL, Américo Pinto. Relatório das Escolas Reunidas de Santo Antônio do Rio Abaixo apresentado ao Diretor Geral da Instrução Pública do Estado, 1930.

CAMARA, Sônia; BARROS, Raphael. Por um projeto escolar modelar: A constituição dos grupos escolares no Distrito Federal em finais do século XIX. In: VIDAL, Diana 
Gonçalves (Org.). Grupos escolares: Cultura escolar primária e escolarização da infância no Brasil (1893 - 1971). Campinas-SP: Mercado de Letras, 2006. p. 277-298.

COSTA. Fernando Corrêa da. Mensagem apresentado a Assembléia Legislativa ao governador do Estado em Mato Grosso. APMT, 1954.

CUNHA. Eduardo Ferreira da. Grupo Escolar, Escola Normal e Escola Modelo "Palácio Da Instrução De Cuiabá" (1900-1915): Arquitetura e Pedagogia. Dissertação (Mestrado em Educação) - UFMT Programa de Pós - Graduação em Educação - IE. Cuiabá, 2009. $132 \mathrm{p}$.

FARIA FILHO, Luciano Mendes de. Dos Pardieiros aos Palácios: cultura escolar e urbana em Belo Horizonte na Primeira República. Passo Fundo: EdUPF, 2000.

FARIA FILHO, Luciano Mendes de; VIDAL, Diana Gonçalves. Os tempos e os espaços no processo de institucionalização da escola primária no Brasil. Revista Brasileira de Educação, n. 14, p.19-34, mai/jun/jul/ago. 2000.

FIGUEIREDO. Arnaldo Estevão de. Mensagem apresentado a Assembléia Legislativa ao governador do Estado em Mato Grosso. APMT, 1949.

. Mensagem apresentado a Assembléia Legislativa ao governador do Estado em Mato Grosso APMT, 1950.

FRAGO, Antonio Viñao. Innovación y Racionalidad Científica - La escuela graduada pública en España (1898 - 1936). Madrid: Akal Universitaria, 1990.

ISOBE, Rogéria Moreira Rezende. A Instituição da Inspetoria Técnica no Âmbito do Projeto de Modernização da Educação Implementado com A Reforma de 1906 em Minas Gerais: estratégia de modelização do ensino. Revista HISTEDBR On-line, SP - Campinas, n.44, p. 107-130, dez - 2011. Disponível em: $\langle$ http://www.histedbr.fae.unicamp.br/revista/edicoes/44/art08_44.pdf $>$ Acesso em: $10 / 02 / 2012$.

LESAGE, Pierre. A pedagogia nas escolas mútuas no século XIX. In: BASTOS, Maria Helena Câmara; FARIA FILHO, Luciano Mendes de (Org.). A escola elementar no século XIX: o método monitorial/mútuo. Passo Fundo: EdIUPF, 1999, pp. 9-24.

MATO GROSSO. Regulamento do Presidente do Estado à Assembléia Legislativa. Cuiabá - APMT, 1910.

Mensagem do Governador do Estado á Assembleia Legislativa de Mato Grosso. Arquivo Público de Mato Grosso - APMT, Cuiabá - MT, 1913.

Direção da Escola Normal e Modelo anexa. Relatório do movimento anual apresentado à Secretaria de Estados dos Negócios do Interior, da Justiça e da Fazenda, 1911.

Relatório da Diretoria Geral da Instrução Pública do Estado de Mato Grosso - Referente ao ano de 1942. Arquivo Público de Mato Grosso - APMT, Cuiabá MT, 1943.

Grosso-APMT, Cuiabá - MT, 1910.

. Relatório do movimento anual do Grupo Escolar de Poconé apresentado à Direção Geral da Instrução Pública. Cuiabá - APMT, 1916.

APMT, 1927.

Regulamento do Presidente do Estado à Assembléia Legislativa. Cuiabá - 
MENDES, Francisco A. Ferreira. Relatório da Diretoria Geral da Instrução Publica de Mato Grosso. APMT, 1942.

MORENO, Gislaene. Terra e poder em Mato Grosso: política e mecanismos de burla (1892-1992). Cuiabá: Entrelinhas; EdUFMT, 2007.

MULLER. Julio Strubing. Relatório apresentado ao Exmo. Sr. Dr. Getulio Vargas Presidente da república em Mato Grosso. APMT, 1940.

PAES, Ademilson Batista. A escola primária rural em Mato Grosso no período republicano (1889-1942). Tese (Doutorado em Educação) - Universidade Estadual Paulista "Júlio de Mesquita Filho". Faculdade de Ciências e Letras, Campus de Araraquara. Araraquara-SP, 2011. 268p.

PIRES. Manoel Ary da Silva. Mensagem apresentada a Assembleia Legislativa lida na abertura da $3^{\text {a }}$ sessão ordinária da sua $1^{\text {a }}$ legislatura, pelo Interventor Federal do Estado de Mato Grosso. APMT, 1937.

POUBEL E SILVA, Elizabeth Figueiredo de Sá. A Escola Normal de Cuiabá: a formação de professores para a implantação do método intuitivo no ensino público mato-grossense. In: NUNES Clarice, SÁ Nicanor Palhares. Instituições Educativas na Sociedade Disciplinar Brasileira. Cuiabá: EdUFMT, 2008

POUBEL E SILVA, Elizabeth Figueiredo de Sá. De criança a aluno: as representações da escolarização da infantil em Mato Grosso (1910 - 1927). Tese (Doutorado em Educação) USP Programa de Pós Graduação da Faculdade de Educação da Universidade de São Paulo. 2006. 220 fls.

REIS, Rosinete M. Palácios da instrução: institucionalização dos grupos escolares em Mato Grosso (1910-1927). Dissertação (Mestrado em Educação) - UFMT Programa de Pós Graduação em Educação, 2005. 240 p.

SÁ. Elizabeth Figueiredo de. De criança a aluno: as representações da escolarização da infantil em Mato Grosso (1910-1927). Cuiabá: EdUFMT, 2007.

SÁ, Elizabeth Figueiredo de, SÁ, Nicanor Palhares. Escola Normal de Cuiabá: formar professores para lapidar almas. In: ARAÚJO, José Carlos Souza, FREITAS, Anamaria G. B. de, LOPES, Antonio Pádua C.(orgs). As escolas normais no Brasil: do Império à República. Campinas-SR: Editora Alínea, 2008, p. 61-74.

SÁ, Nicanor Palhares; SÁ, Elizabeth Figueiredo de. A escola pública primária matogrossense no período republicano (1900-1930) In: . Revisitando a história de escola primária: os grupos escolares em Mato Grosso na Primeira República. Cuiabá: EdUFMT, 2011. p.29- 54 .

SCHUELER, Alessandra Frota Martinez de. Grandeza da Pátria e Riqueza do Estado: Expansão da Escola Primária no Estado do Rio de Janeiro (1893-1930). Revista de Educação Pública - v. 19, n. 41 (set./dez. 2010) Cuiabá, EdUFMT, 2010, p. 535-550.

SCHUELER, Alessandra Frota Martinez de; MAGALDI, Ana Maria Bandeira de Mello. Educação escolar na Primeira República: Memória, História e perspectivas de Pesquisa. Revista Tempo. v. 13, n. 26, 2009, p. 32-55. Disponível em: <http://www.scielo.br/pdf/tem/v13n26/a03v1326.pdf>. Acesso em: 01/07/2012.

SCHUELER, Alessandra Frota Martinez de; SÁ. Elizabeth Figueiredo de; FERRO, Maria do Amparo Borges. A expansão da escola primária graduada nos Estados na Primeira República: a ação dos poderes públicos. In: SOUZA, Rosa Fátima de; SILVA, Vera Lucia Gaspar da; SÁ, Elizabeth Figueiredo de, (Orgs.). Por uma teoria e uma história da escola 
primária no Brasil: investigações comparadas sobre a Escola Graduada (1870 - 1930) 2011. Prelo. 128-141p.

SILVA Franklin Cassiano da. Mensagem apresentado a Assembléia Legislativa ao governador do Estado em Mato Grosso. APMT, 1950.

SILVA, A. M. Práticas Educativas no Grupo Escolar Tenente Coronel José Correia, em Assú/RN (1911-1927). Revista do Núcleo Câmara Cascudo de Estudos Norte-RioGrandenses/UFRN. n. 1, fev. 2010. Disponível em: <http://www.periodicos.ufrn.br/ojs/index.php/imburana/article/view/860/794 >. Acesso em: 10/05/2012.

SOUZA, Rosa Fátima. Espaço da Educação e da Civilização: origens dos grupos escolares no Brasil. In: O Legado Educacional do Século XX. Araraquara: UNESP - Faculdade de Ciências e Letras, 1998.

Alicerces da Pátria: escola primária e cultura escolar no estado de São Paulo (1890-1976), Araraquara, 2006, 367f. Tese (Livre-Docência) - Faculdade de Ciências e Letras, Universidade Estadual Paulista, Araraquara, 2006.

História da organização do trabalho escolar e do currículo no século XX: ensino primário e secundário no Brasil. São Paulo: Cortez, 2008. 319 p.

TOLEDO, Annibal. Mensagem apresentação à Assembléia Legislativa e lida na abertura da $1^{a}$ Sessão na abertura de sua $15^{a}$ Legislatura Mato Grosso. APMT, 1950.

TORRES, Rosane dos Santos. Filhos da Pátria, Homens pelo Progresso: O Conselho Municipal e a Instrução Pública na Capital Federal (1892-1902). Dissertação (Mestrado em História) - UERJ Programa de Pós-graduação. Rio de Janeiro 2009. 172 p.

VIDAL, Diana Gonçalves. Culturas Escolares: estudo sobre as práticas de leitura e escrita na escola pública primária (Brasil e França, final do século XIX). Campinas - SP: Autores Associados, 2005.

.Tecendo história (e recriando memória) da escola primária e da infância no Brasil: os Grupos Escolares em foco. In: VIDAL, Diana (org.) Grupos Escolares: cultura escolar primária e escolarização da infância no Brasil (1893-1971). Campinas: SP: Mercado de Letras, 2006, p. 7-20.

\footnotetext{
${ }^{1}$ Mestre em Educação pela UFMT. Doutorando em Educação pela UNESP - Rio Claro. Professor Substituto da UFMT/DEOE, e-mail: eltoncastr@gmail.com. Esta pesquisa é um desdobramento do Projeto intitulado "Entre Caminhos, Livros, Professores e Estudantes: As Escolas Primárias em Mato Grosso (1930-1960)", aprovado pela Fundação de Amparo à Pesquisa do Estado de Mato Grosso - FAPEMAT, processo $\mathrm{n}^{\circ}$ $154805 / 2014$.
}

Recebido: dezembro-13 Aprovado: dezembro-14 